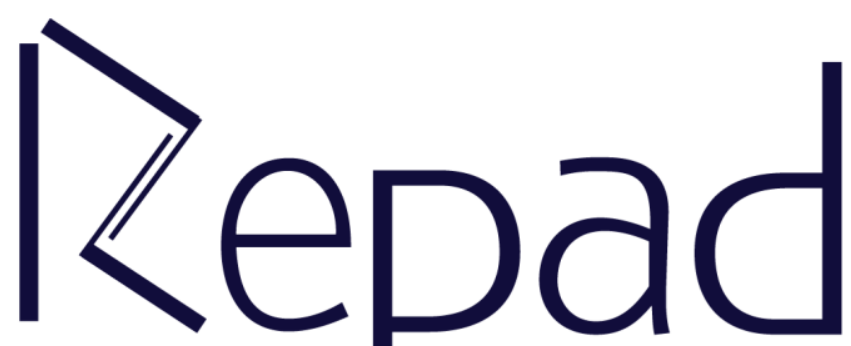

v. 4, n. 2, Maio-Agosto/2020

Revista Estudos e

Pesquisas em Administração 


\title{
ESTUDO DA POSSIBILIDADE DE IMPLANTAÇÃO DE UMA GESTÃO PARTICIPATIVA EM UMA LOJA DE VAREJO NA CIDADE DE JUAZEIRO- BA
}

\author{
Carmicelia Fidiel dos Santos Cajuí \\ carmicelia@gmail.com \\ http://orcid.org/0000-0001-6798-8293 \\ Faculdade São Francisco de Juazeiro \\ Juazeiro-Bahia, Brasil \\ Patricia Emanuelle Araujo \\ http://orcid.org/0000-0003-0815-6520 \\ Faculdade São Francisco de Juazeiro \\ Juazeiro-Bahia, Brasil \\ Mercia Maria da Silva Souza \\ http://orcid.org/0000-0003-4850-2854 \\ Faculdade São Francisco de Juazeiro \\ Juazeiro-Bahia, Brasil \\ Florisvaldo Cunha Cavalcante Junior \\ http://orcid.org/0000-0002-6306-0380 \\ Instituto Federal do Sertão Pernambucano \\ Juazeiro-Bahia, Brasil
}

\section{Resumo}

A gestão participativa, um tema pouco adotado no âmbito empresarial que é o processo de tomadas de decisão sobre a administração das organizações, contribui para as melhorias no ambiente de trabalho, onde os gerentes participam das decisões junto com os gestores da empresa. Assim, o artigo apresenta como objetivo analisar a possibilidade da gestão participativa para o desempenho das atividades em loja de varejo na cidade de Juazeiro Bahia. Conhecer a gestão participativa nesse estudo de caso é expor comparações entre as ideias dos gestores com os gerentes. O presente trabalho foi desenvolvido através de uma pesquisa bibliográfica e descritiva, aplicando assim um questionário de 8 questões para 3 gestores e 11 gerentes, onde foi evidenciado através da pesquisa que a empresa tem interesse na implantação da gestão participativa para a melhoria do desempenho das atividades na organização. Conclui-se que para a implantação da gestão participativa requer mudanças de comportamentos não só da chefia, mas também de todos os gerentes vale ressaltar que tomar iniciativa, agir, discutir, questionar e sugerir devem ser ações espontâneas e voluntárias, portanto, sem adequação na empresa não há possibilidade de uma gestão participativa.

Palavras-chave: Gestão Participativa; Decisões; Implantação. 


\title{
STUDY OF THE POSSIBILITY OF IMPLEMENTING A PARTICIPATIVE MANAGEMENT IN A RETAIL STORE IN THE CITY OF JUAZEIRO-BA
}

\begin{abstract}
Participatory management, a theme little adopted in the business environment, which is the decision-making process about the management of organizations, contributes to improvements in the work environment, where managers participate in decisions together with company managers. Thus, the article aims to analyze the possibility of participatory management for the performance of activities in a retail store in the city of Juazeiro Bahia. To know the participative management in this case study is to expose comparisons between the managers' ideas with the managers. The present work was developed through a bibliographic and descriptive research, thus applying a questionnaire of 8 questions for 3 managers and 11 managers, where it was evidenced through the research that the company is interested in the implementation of participative management to improve the performance of activities in the organization. It is concluded that for the implementation of participative management it requires changes in behaviors not only of the head, but also of all managers, it is worth mentioning that taking initiative, acting, discussing, questioning and suggesting must be spontaneous and voluntary actions, therefore, without adaptation in there is no possibility of participatory management.
\end{abstract}

Keywords: Participatory Management; Decisions; Implantation.

Submetido: $20 / 04 / 2020$

Aceito: $12 / 05 / 2020$

Publicado: 31/05/2020

\section{Introdução}

A empresa estudada já está há 45 anos no mercado, iniciou suas atividades com o ramo em tecidos na cidade de Remanso, estado da Bahia, atualmente com 16 lojas em diversas cidades na Bahia, Pernambuco e Piauí, com um quadro funcional de 240 colaboradores.

A gestão participativa representa um estágio liberal da gestão das pessoas, transformando em parceiros do negócio para o desenvolvimento das organizações nas tomadas de decisão das empresas, tirando a centralização hierárquica e distribuindo para os funcionários fazendo com que eles sejam mais participativos mostrando suas atribuições e capacitação para determinada atividade.

Para Maximiano (1995, p.15), não há receitas ou fórmulas para a gestão participativa, pois se trata muito mais de uma filosofia do que uma técnica. Cada empresa precisa descobrir o seu método de gestão participativa. Primeiramente o gestor deverá estar pronto para aceitações das opiniões e críticas dos funcionários, por essa razão quando se têm várias ideias juntas ajuda a empresa na buscado seu objetivo.

Portanto, um processo participativo que utiliza a competência total dos funcionários, e se destina a encorajar o maior comprometimento com o sucesso da organização, sendo assim criando um vínculo entre empresa e colaborador. Nesse sentido, a gestão participativa é um estado liberal das pessoas nas tomadas de decisão, 
onde terão a oportunidade de questionar, discutir e sugerir para o alcance dos objetivos aonde se quer chegar.

Para Chiavenato (2015, p. 89), “a gestão participativa é uma forma de gestão na qual as pessoas têm reais possibilidades de participar, com liberdade de questionar, discutir, sugerir, modificar, alterar, questionar uma decisão um projeto ou uma simples proposta". Para o mesmo autor, isso não significa destruir ou anular os centros de poder, pois a gestão participativa é perfeitamente compatível com a hierarquia. Desse modo, o presente artigo buscará responder a seguinte questão: Como a implantação da gestão participativa poderá motivar em uma loja de varejo na cidade de Juazeiro Bahia?

A gestão participativa tem a motivação como uma ferramenta de altíssimo valor, valorizando as pessoas em todos os aspectos dentro das organizações, sendo assim aprimorando a satisfação e motivação no ambiente de trabalho.

Conforme Maximiano (1995, p. 38), a motivação para o trabalho é a disposição ou interesse para executar uma tarefa ou decidir-se um determinado tipo de trabalho.

Assim, o artigo tem como objetivo de verificar os fatores que impossibilitam os empregados de desempenharem a gestão participativa, buscando também identificarem as vantagens e desvantagens.

O que justifica este artigo é que a Gestão Participativa tem demonstrado para crescimento e sucesso das organizações e revela que forma ela vem contribuindo para um melhor desempenho dos líderes na gestão de pessoas, considerando, de forma geral, que quando os funcionários são valorizados, eles sentem-se animados a colaborar para que a empresa atinja seus objetivos. Sendo assim, neste mundo globalizado e competitivo, as empresas que não valorizam seus funcionários, não os integram no processo de trabalho, que se sintam motivados, satisfeitos, envolvidos e comprometidos com o trabalho, dificilmente se mantêm no mercado.

Portanto, quando uma organização usa a gestão Participativa, esta oferece a oportunidades de um funcionário ser autônomo e mais responsável, proporcionando assim, um bem estar para a empresa e para aqueles que nela trabalham.

Ao permitir que os colaboradores participem com suas experiências e conhecimentos, de forma organizada e responsável, os benefícios de uma correta tomada de decisões revertem em interesse para a organização. Portanto, funcionários que se sentem mais valorizados, são mais produtivos e mais comprometidos, pois se sentem mais motivados (CHIAVENATO, 2015).

\section{Gestão Participativa}

Neste tópico serão abordados autores da área da gestão participativa, que propicionaram a estrutura para entendimento do tema proposto nesse artigo.

Com a elevação dos níveis de produtividade, incentivados pela competitividade crescente, surgiu a necessidade de manter um bom nível de satisfação entre os funcionários, para que estes possam responder às demandas por produtividade, com esse propósito surgem novos modelos de administração menos rígidos e um desses modelos é exatamente a gestão participativa.

Para Bordenave (1983, p. 16), "a participação é o caminho natural para o homem exprimir sua tendência inata de realizar, fazer coisas, afirmar-se a si mesmo e dominar a natureza e o mundo". A gestão participativa ou ideia de participação teve início, desde antiguidade, a mesma nasceu na Grécia, com o nome de democracia. 
Sendo assim, a gestão participativa foi abordada nos anos 1970 a 1980 depois da Segunda Guerra Mundial, após os anos 1980 ela foi mais divulgada na revolução Japonesa que favoreceu para exposição dos métodos da gestão participativa.

Participação consiste basicamente na criação de oportunidades para que as pessoas influenciem decisões que a afetarão. Essa influência pode variar pouco ou muito. Participação é um caso especial de delegação, na qual o subordinado obtém maior controle, maior liberdade de escolha em relação às suas próprias responsabilidades (MARANALDO, 1989, p 60).

Nesse sentido, para a empresa implantar a gestão participativa precisa da participação entre gestores e gerentes, o mais simples é aprimorar a comunicação, que costuma ser precária especialmente entre a base e o topo. Diante disso necessitará ter um processo de liderança baseado na confiança, portanto ajudará na tomada de decisão da empresa.

A gestão participativa tem sido apontada por empresas bem-sucedidas, principalmente, nos últimos anos, como a alavanca para o progresso, tendo por base as pessoas. Representa o envolvimento do capital intelectual na gestão da empresa. $\mathrm{Na}$ realidade, a gestão participativa é uma evolução de processo democrático de participar e decidir (CHIAVENATO, 2015).

Verifica-se que a gestão participativa se caracteriza por um modelo liberal de administração que envolve gerentes e funcionários num processo de participação contínua, que deve ser sempre incentivado pelos gerentes através da motivação e do envolvimento a ponto de assumirem responsabilidades das decisões na empresa.

A participação nesse processo, diz respeito à motivação individual de cada individuo, às habilidades, passa pela liderança e pela dinâmica de grupo e incluem até fatores organizacionais, estruturas sociopolíticas, processos em cada sociedade e entre sociedades. Os empregados querem contribuir e opinar sobre os assuntos que os afetam, tais como definição dos objetivos de trabalho e solução de problemas de produtividade e qualidade. Isto faz com que se sintam importantes valorizados (KANAANE, 1999).

A tomada de decisão é um processo responsável pela escolha da melhor solução para um problema ou oportunidade, dependendo do contexto, o processo decisório é considerado difícil e uma vez feito poderá ocasionar em consequências positivas ou negativas. Conforme Maximiano (2000, p. 139), decisões são escolhas que as pessoas fazem para enfrentar problemas e aproveitar oportunidades.

A partir de vários conhecimentos e experiências, o processo decisório pode ser um facilitador na tomada de decisão. Observa-se que o trabalhador começa a conquistar aos poucos o seu espaço, tendo mais participação e reconhecimento no trabalho humano, se tornando como fator principal e colaborando com o processo decisório nas organizações.

De acordo com Lerner (1996, p.33), a participação de cada indivíduo garante uma composição de forças, onde o "todo", trabalhando junto, tenha mais poder do que a soma das partes isoladas. Um fator importante na gestão participativa são as vantagens onde geram ideias diferentes sobre o mesmo assunto, dando ao gestor a possibilidade de escolha, além de uma visão ampla em suas áreas de atuação.

A gestão participativa aumenta em muito a visão de novas ideias, são possibilidades que temos com a colaboração de mais pessoas, que tem ângulos de visão 
e níveis de conhecimento diferenciado. Este desenvolvimento gera alternativas positivas e mais agilidades para o alcance dos objetivos.

Uma boa gestão participativa só é possível quando o principal líder da empresa presidente ou acionista estiver convicto de que é possível tê-la e se ele mesmo patrocinar esse processo. Segundo Chiavenato (2015, p. 88), "a gestão participativa somente funciona quando os executivos a fazem funcionar".

Para Victor e Bryto $(2019$, p. 4), “o líder só terá apoio da sua equipe mediante a conquista diária, ele deve participar das atividades e está acompanhando a todo o momento para orientar as pessoas". Por outro, lado os liderados precisam atentar para o fato de que "são peças essenciais na obtenção desses resultados, percebendo que ao se adequar de forma assertiva nas estratégias propostas, tornam visíveis seus esforços e bom desempenho diante dos objetivos organizacionais" (LIMA; BRYTO, 2018, p. 96).

Com a implantação da gestão participativa de seus colaboradores, há a descentralização dos cargos e assim, cada um ganha uma autonomia e independência para as tomadas de decisão, tanto da parte do cargo mais alto, quanto do mais baixo da organização, nesse sentido passando um pouco de responsabilidades para um grupo de pessoas com habilidades para o trabalho indicado. Segundo Chiavenato (2015), o executivo deve assegurar os seguintes pré-requisitos para o sucesso da participação das pessoas:

Uma equipe adequada para haver participação eficaz; os benefícios potenciais de participar devem ser maiores do que os custos de participar; a participação deve também relevar os objetivos e interesses individuais a serem alcançados; a participação deve utilizar as habilidades adequadas de cada pessoa para lidar com tarefa; a participação deve se basear em uma capacidade mútua de comunicação; muita confiança: não deve haver sentimento de medo de nenhuma parte; ampla liberdade de trabalho (CHIAVENATO, 2015, p.91).

Nesse sentido, para o sucesso da gestão participativa tem que haver um engajamento onde são necessárias energias físicas, mentais e emocionais a serviço da organização, a gestão participativa requer garra, volume de esforços por parte das pessoas e para transformar seus colaboradores em elementos comprometidos à empresa precisa ter um bom relacionamento, um ambiente de trabalho agradável, uma boa comunicação, mensagens positivas e um estilo de gestão aberta e democrática.

\section{Procedimentos Metodológicos}

A metodologia utilizada baseou-se em uma pesquisa descritiva dedutiva, pois descreve as particularidades do objeto de estudo, designando o tema da gestão participativa.

Nesse trabalho foi feita pesquisa bibliográfica para a elaboração do tema escolhido. Conforme Gil (2002, p. 48), a pesquisa bibliográfica é desenvolvida a partir do material já elaborado, constituído principalmente de livros e artigos científicos. De acordo com autor, a pesquisa realizada por meio de livros e artigos científicos é de grande importância para o enriquecimento do trabalho, pois é através da pesquisa que determinamos os objetivos a serem alcançados. 
Para a realização da pesquisa foi formulado um questionário com 8 (oito) questões iguais de múltipla escolha e aplicado em loja de varejo na cidade de JuazeiroBahia para os gestores e gerentes onde foi feito uma comparação entre as respostas.

Conforme Cervo (2007, p. 52), o questionário é uma forma mais usada para coletar dados, pois possibilita medir com mais exatidão o que se deseja. De acordo com autor possibilitando a tabulação dos dados que favorecem as condições de um raciocínio lógico e o resultado satisfatório para o estudo do tema abordado.

A gestão participativa, porém, é uma maneira de integrar funcionários onde há discussão sobre um assunto tanto positivo como negativo de uma empresa. As propostas são adequadas para que os funcionários se sintam satisfeito e o trabalho tenha êxito e grande qualidade.

\section{Análise dos Resultados e Discussão}

Os dados coletados foram tabulados e apresentados em dois blocos, sendo as respostas dos gerentes e, em seguida, as respostas dos gestores (proprietários).

\subsection{Informações do Questionário dos Gerentes}

Questão 1: Eu me sinto livre e a vontade para falar sobre meu trabalho com os funcionários da minha unidade?

Conforme Gráfico 1, 64\% os gerentes concordam totalmente para falar sobre o seu trabalho com os funcionários, contra $18 \%$ dos gerentes que concordam e discordam parcialmente. Portanto, os gerentes da empresa estudada sentem-se a vontade para a comunicação dentro do ambiente de trabalho na empresa com os seus colaboradores, conforme Gráfico 1.

Gráfico 1. Resultado da pergunta 1

\begin{tabular}{|l|l|}
\hline & $1:$ Nem discordo e nem concordo \\
& 2: Discordo totalmente \\
& 3: Discordo parcialmente \\
& $4:$ Concordo parcialmente \\
& 5: Concordo totalmente
\end{tabular}

Fonte. Elaborado pelos autores

Questão 2: As informações na minha unidade fluem naturalmente em todos os sentidos: para cima, para baixo e lateralmente (do gerente aos subordinados, dos subordinados para o gerente, entre o gerente e os subordinados)?

Em relação à pergunta 2 com $46 \%$, concordam parcialmente que as informações fluem naturalmente entre gerentes e subordinados, 36\% discordam parcialmente, $9 \%$ nem discorda e nem concorda e $9 \%$ concordam totalmente. Nesse sentido a maioria dos gerentes concorda que as informações são passadas dentro da empresa, conforme Gráfico 2. 
Gráfico 2. Resultado da pergunta 2

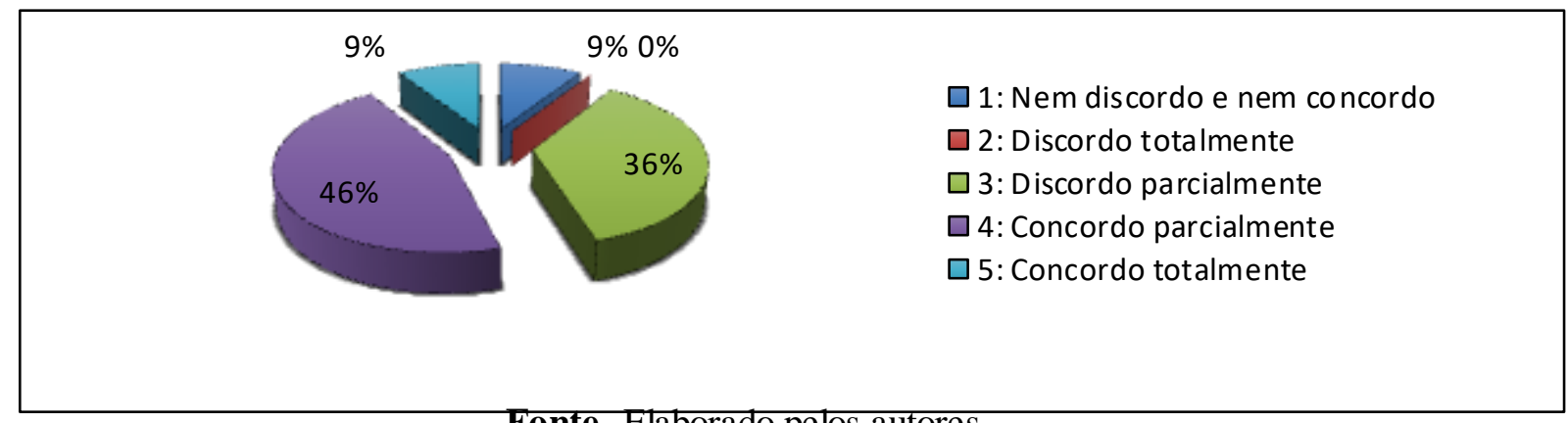

Fonte. Elaborado pelos autores

Questão 3: Há interação, com elevado grau de confiança entre mim e os funcionários da minha unidade?

Em relação à pergunta 3, o grau de confiança entre gerentes e funcionários foi de $37 \%$ concordando parcialmente, $36 \%$ concordaram totalmente e $27 \%$ discordaram parcialmente. A maioria dos gerentes concordam que tem uma confiança dentro do ambiente de trabalho, portanto contribuindo muito para implantaçãoda gestão participativa na empresa estudada, conforme Gráfico 3.

Gráfico 3. Resultado da pergunta 3

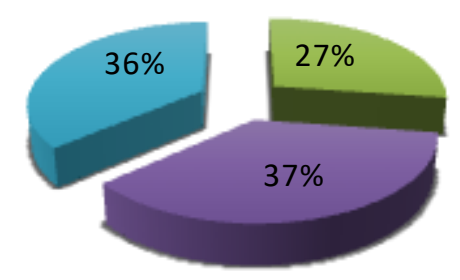

1: Nem discordo e nem concordo

2: Discordo totalmente

3: Discordo parcialmente

4: Concordo parcialmente

Fonte. Elaborado pelos autores

Questão 4: Meus funcionários proporcionam um ambiente para trabalho cooperativo, ou seja, prevalece o espírito de equipe?

De acordo com à pergunta 4,73\% dos gerentes concordam parcialmente em relação a cooperação dos funcionários e o espírito de equipe, $9 \%$ nem discorda e nem concorda, $9 \%$ discorda totalmente e $9 \%$ concordam totalmente. Conforme o gráfico ele evidencia que a maioria dos colaboradores proporciona e prevalece um ambiente cooperativo prevalecendo um espírito de equipe, conforme Gráfico 4.

Gráfico 4. Resultado da pergunta 4
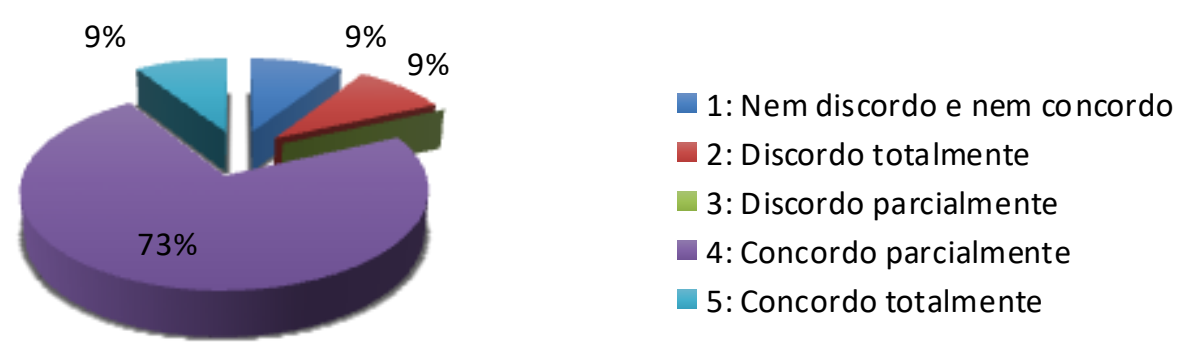

Fonte. Elaborado pelos autores 
Questão 5: O processo de tomar decisões é bem integrado e ocorre em toda a minha unidade, por meio de grupos que se comunicam?

De acordo com a pergunta 5, 37\% dos gerentes discordam parcialmente com relação ao processo de tomadas de decisões que ocorrem na unidade através de grupos, $36 \%$ concordam parcialmente, $18 \%$ discordam totalmente e $9 \%$ nem discordam e nem concordam. Nessa pergunta o gráfico mostra que não é bem integrado o processo de tomada de decisões dentro da empresa, precisando ser melhorado, conforme Gráfico 5.

Gráfico 5. Resultado da pergunta 5

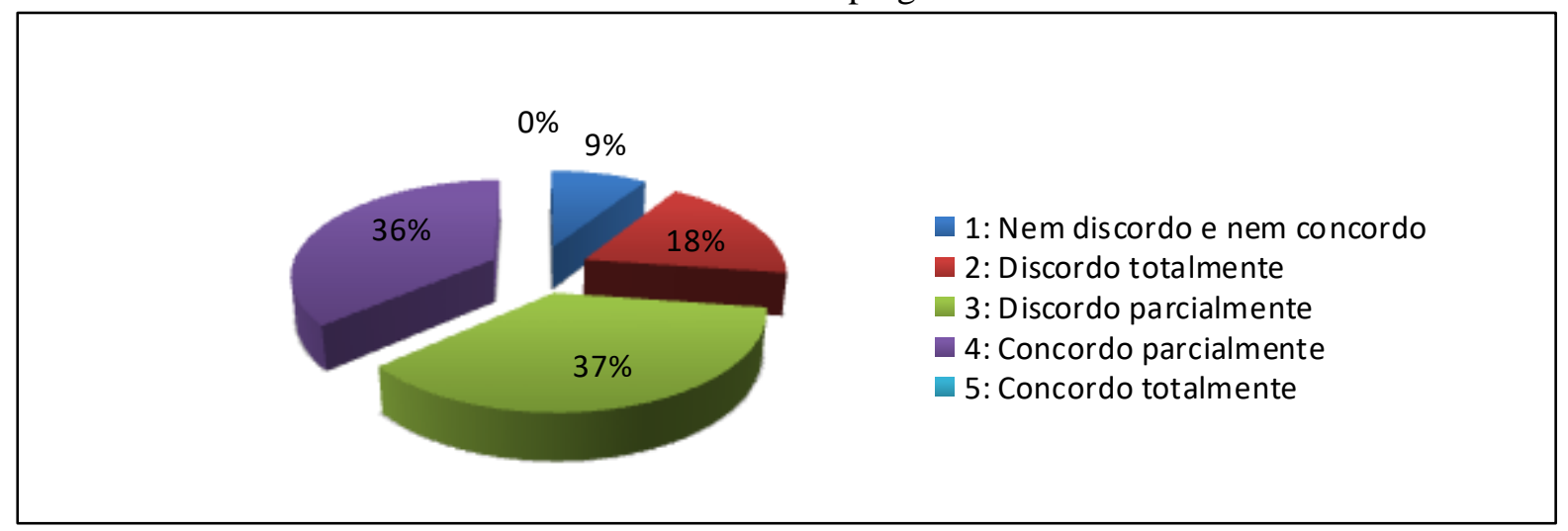

Fonte. Elaborado pelos autores

Questão 6: As minhas decisões ajudam a desenvolver motivação suficiente para implementá-las na minha empresa?

Com base na pergunta 6,37\% dos gerentes concordam parcialmente em relação a tomada de decisões no desenvolvimento da motivação para execução na empresa, $36 \%$ concordam totalmente, $9 \%$ discordam totalmente, $9 \%$ discordam parcialmete e $9 \%$ nem discordam e nem concordam. Nessa gráfico buscaram-se descobrir se as decisões contribuem para a motivação entre gerentes e colaboradores dentro do ambinte de trabalho, onde o resultado encontrado precisa ser melhorado dentro da organização, conforme Gráfico 6.

Gráfico 6. Resultado da pergunta 6

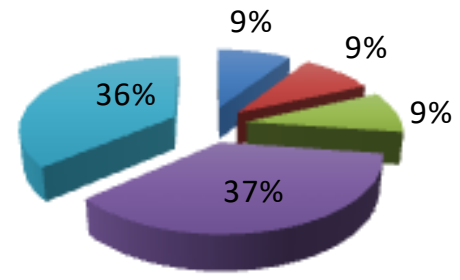

$$
\begin{aligned}
& \text { 1: Nem discordo e nem concordo } \\
& \text { 2: Discordo totalmente } \\
& \text { 3: Discordo parcialmente } \\
& \text { 4: Concordo parcialmente } \\
& \text { 5: Concordo totalmente }
\end{aligned}
$$

Fonte. Elaborado pelos autores

Questão 7: Fora as emergências, as metas e objetivos da minha unidade são definidos por meio da participação coletiva?

Em relação à pergunta $7,37 \%$ concordam parcialmemte dos gerentes responderam que as emergências, metas e objetivos são definidos por meio da participação coletiva, $27 \%$ discordam totalmente, $18 \%$ discordam parcialmente, $9 \%$ 
nem discordam e nem concordam, e $9 \%$ concordam totalmente. Conforme o gráfico da alternativa acima foi percebido que há um ponto positivo onde a maioria dos gerentes acreditam na possibilidade da gestão particpativa na empresa, conforme Gráfico 7.

Gráfico 7. Resultado da pergunta 7

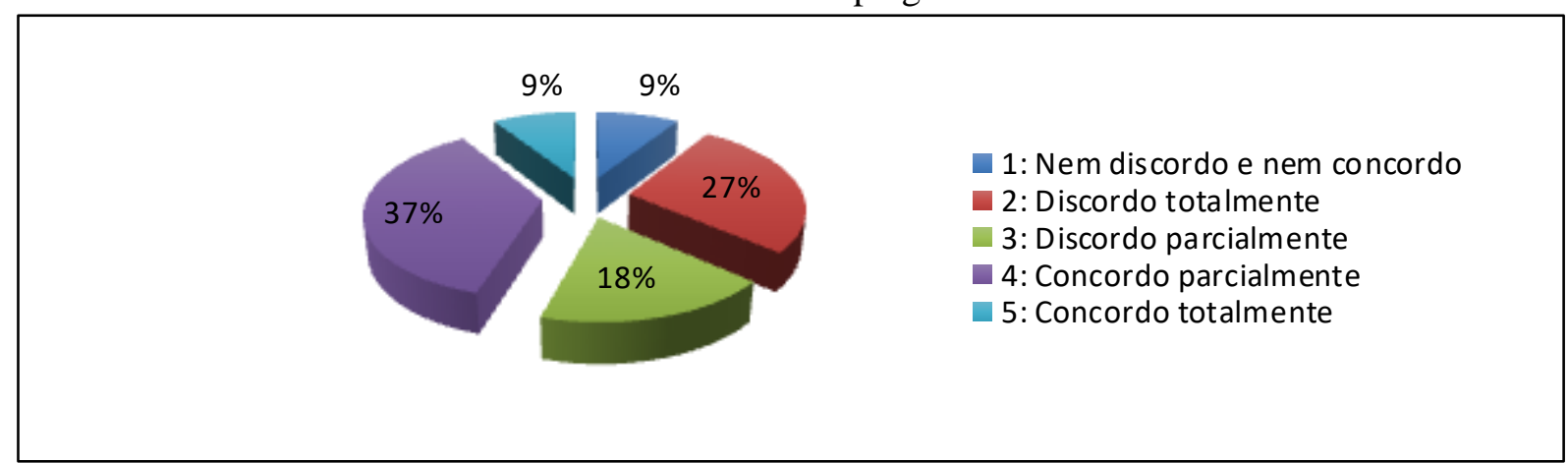

Fonte: Elaborado pelos autores

Questão 8: Os funcionários da minha unidade valorizam minhas ideias e opiniões e tentam fazer uso construtivo delas?

De acordo com a pergunta $8,37 \%$ dos gerentes concordam parcialmente na valorização das ideias e opiniões e tentam fazer uso delas, $27 \%$ discordam parcialmente, $18 \%$ nem discordam e nem concordam e $18 \%$ concordam totalmente. Portanto, no gráfico abordado pode-se observar que há respostas muito parecidas, mas com um ponto positivo, percebendo-se que os gerentes acreditam que suas ideias e opiniões vão valorizadas, conforme Gráfico 8.

Gráfico 8. Resultado da pergunta 8

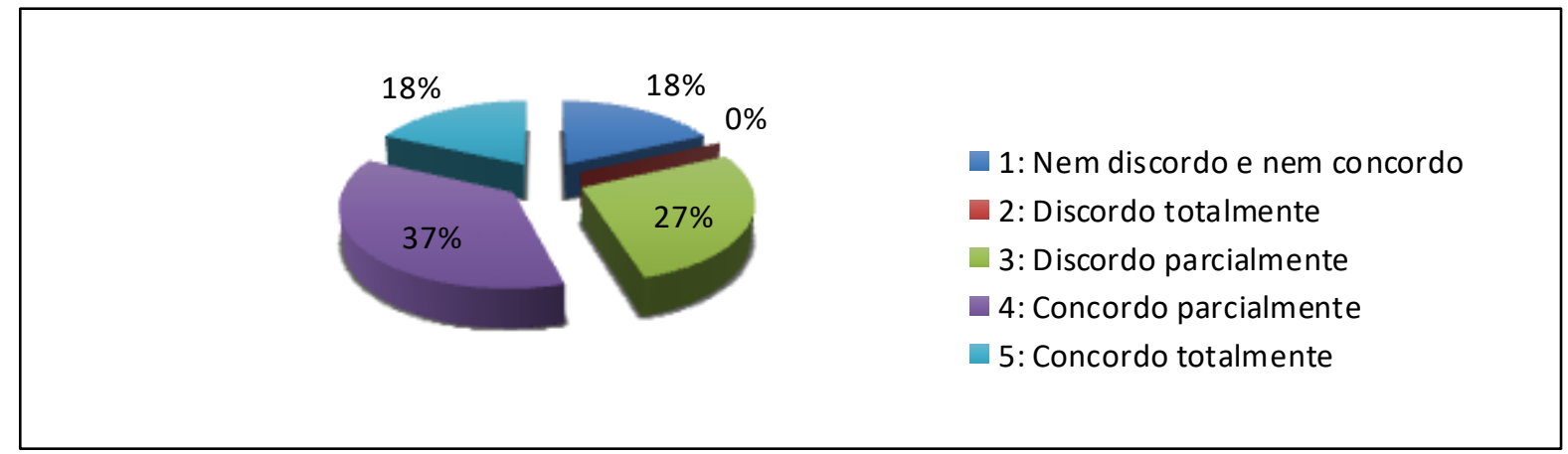

Fonte. Elaborado pelos autores

\subsection{Informações do Questionário dos Gestores}

No que se refere ao ponto de vista dos gestores (proprietários), os dados foram tabulados e as considerações serão apresentadas nessa seção. 
Questão 1: Meus funcionários se sentem livres e a vontade para falar sobre a minha empresa e comigo na unidade?

Em relação a pergunta 1, 100\% dos gestores concordam totalmente para falar sobre a sua empresa com os funcionários. O Gráfico 9 indica claramente que os gestores da empresa não tem nenhum problema em relação ao diálogo entre os funcionários, um ponto forte para a implantação.

Gráfico 9. Resultado da pergunta 1

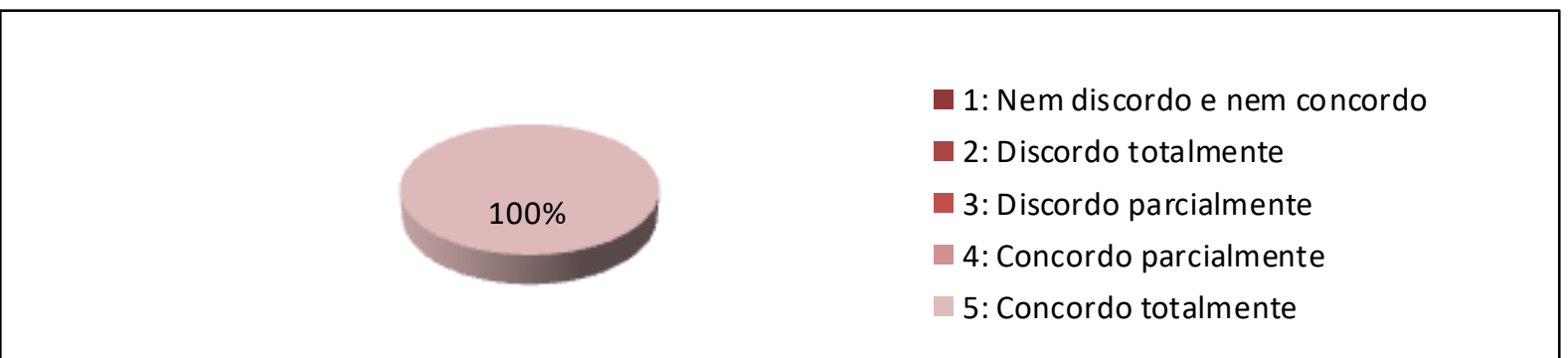

Fonte. Elaborado pelos autores

Questão 2: As informações na empresa fluem naturalmente em todos os sentidos: para cima, para baixo e lateralmente (do chefe aos subordinados, dos subordinados para o chefe, entre o chefe e os subordinados)?

Em relação à pergunta 2, $100 \%$ dos gestores concordam parcialmente que as informações fluem naturalmente entre gestores e subordinados. O Gráfico 10 relata que precisam ser melhoradas as informações que são passadas dentro da empresa.

Gráfico 10. Resultado da pergunta 2

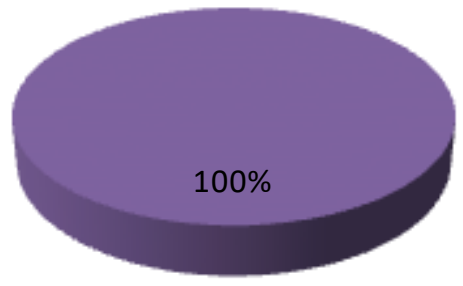

1: Nem discordo e nem concordo

2: Discordo totalmente

3: Discordo parcialmente

4: Concordo parcialmente

5: Concordo totalmente

Fonte: Elaborado pelos autores

Questão 3: Há interação, com elevado grau de confiança entre mim e os funcionários da minha empresa?

Em relação a pergunta 3, o grau de confiança entre gestores e funcionários foi de $67 \%$ concordando totalmentee $33 \%$ concordaram parcialmente. Diante do Gráfico 11, percebece-se que na opinão dos gestores a empresa tem uma confiança em seus colaboradores, portanto, mais um ponto positivo para a implantação da gestão participativa na empresa estudada. 
Gráfico 11. Resultado da pergunta 3

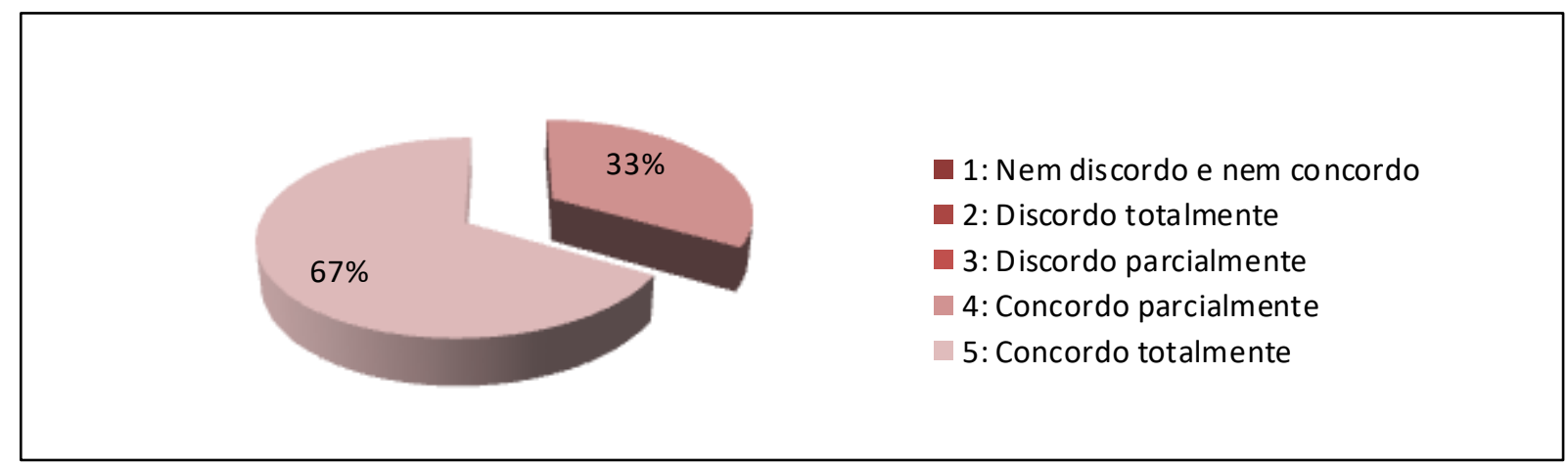

Fonte. Elaborado pelos autores

Questão 4: Meus funcionários proporcionam um ambiente para trabalho cooperativo, ou seja, prevalece o espírito de equipe?

De acordo com a pergunta 4, 67\% dos gestores discordam parcialmente em relação á cooperação dos funcionários e o espírito de equipe e 33\% discordam totalmente. No Gráfico 12, buscaram-se descobrir a possibilidade da implantação da Gestão Participativa, onde os gestores estão mais para discordar que para concordar, no entanto não quer dizer que não tenha a possibilidade da implantação na empresa.

Gráfico 12. Resultado da pergunta 4

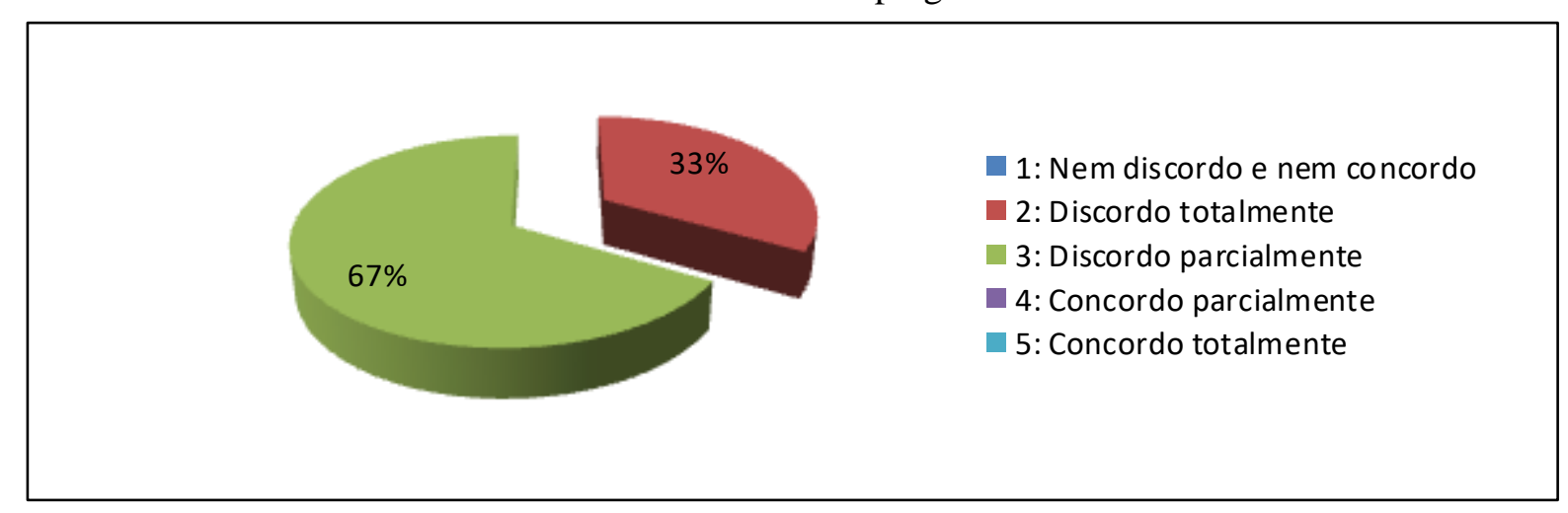

Fonte. Elaborado pelos autores

Questão 5: O processo de tomar decisões é bem integrado e ocorre em toda a minha empresa, por meio de grupos que se comunicam?

De acordo com a pergunta $5,34 \%$ dos gestores discordam totalmente com relação ao processo de tomadas de decisões que ocorrem na sua empresa por meio de grupos, $33 \%$ discordam parcialmente, e $33 \%$ concordam parcialmente. Evidencia-se que as respostas foram bem parecidas entrem os gestores, uma área que precisa ser melhorada onde a comunicação em grupo para uma gestão participativa é essencial na empresa, conforme Gráfico 13. 
Gráfico 13. Resultado da pergunta 5

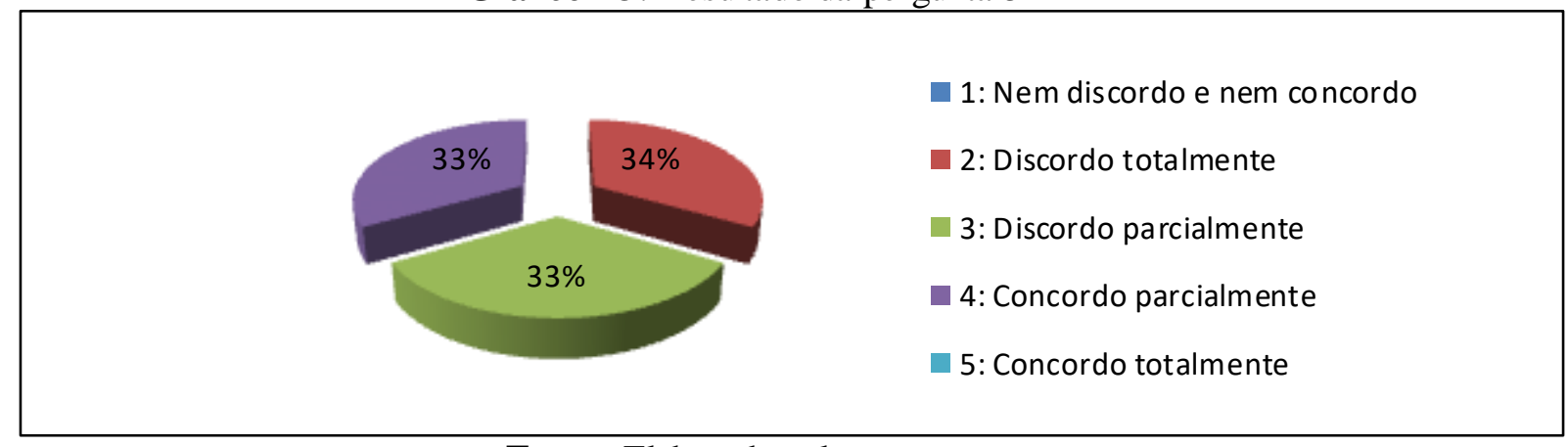

Fonte. Elaborado pelos autores

Questão 6: As minhas decisões ajudam a desenvolver motivação suficiente para implementá-las na minha empresa?

Com base na pergunta $6,67 \%$ dos gestores concordam parcialmente em relação a tomada de decisões no desenvolvimento da motivação para execução na sua empresa e $33 \%$ discordam totalmente. De acordo com o Gráfico 14, a maioria dos gestores confirmam que as decisões tomada por eles ajudam nas atividades da empresa.

Gráfico 14. Resultado da pergunta 6

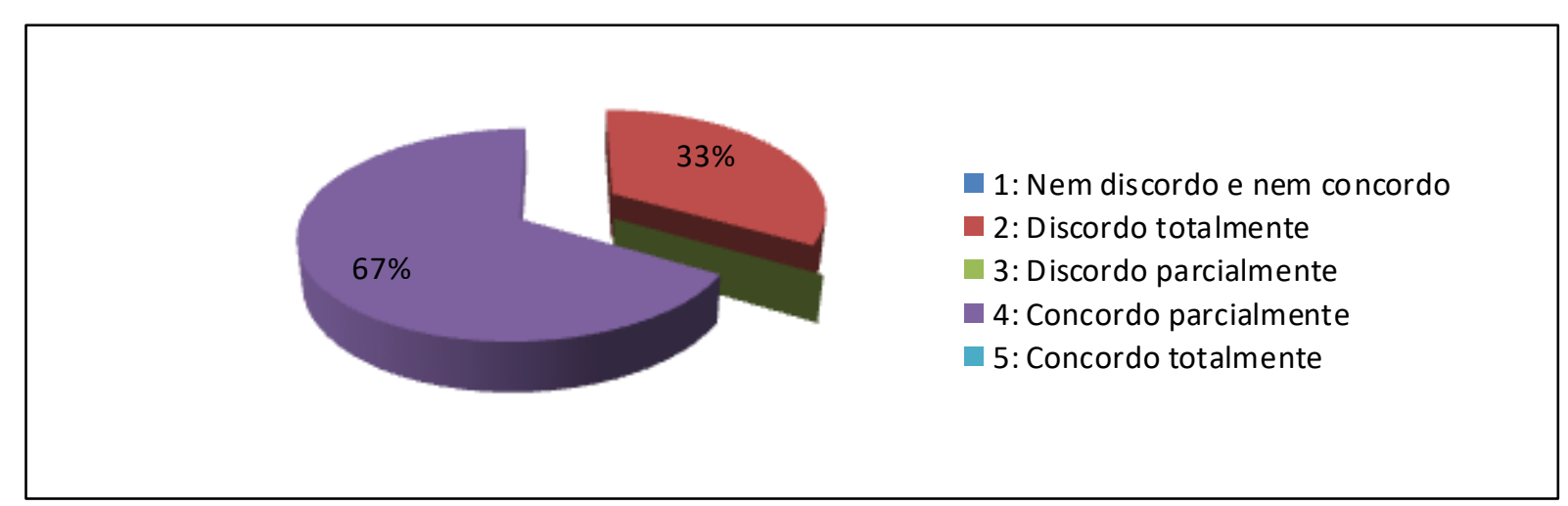

Questão 7: Fora as emergências, as metas e objetivos da minha empresa são definidos por meio da participação coletiva?

Em relação a pergunta 7,67\% dos gestores discordam parcialmente que as emergências, metas e objetivos são definidos por meio da participação coletiva, $33 \%$ concordam parcialmente. Quanto ao Gráfico 15, este relata que os gestores da empresa não concordam, mas por essa razão a empresa ela não possui uma gestão participativa, apenas está sendo estudado a possibilidade da implantação para a melhoria do andamento na organização. 
Gráfico 15. Resultado da pergunta 7

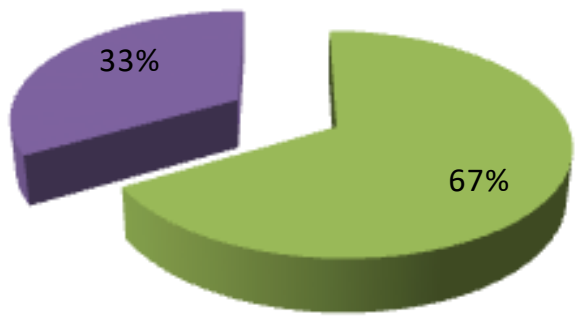

1: Nem discordo e nem concordo

2: Discordo totalmente

3: Discordo parcialmente

4: Concordo parcialmente

5: Concordo totalmente

Fonte. Elaborado pelos autores

Questão 8: Os funcionários da minha empresa valorizam minhas ideias e opiniões e tentam fazer uso construtivo delas?

De acordo com a pergunta 8,67\% dos gestores discordam parcialmente acercada valorização das suas ideias e opiniões dos funcionários e $33 \%$ discordam totalmente. $\mathrm{O}$ objetivo dessa questão foi saber, se na opinião dos gestores, suas ideias e opiniões são valorizadas e aproveitadas pelos gerentes, onde foi percebido que a maioria dos gestores discorda, conforme Gráfico 16.

Gráfico 16. Resultado da pergunta 8

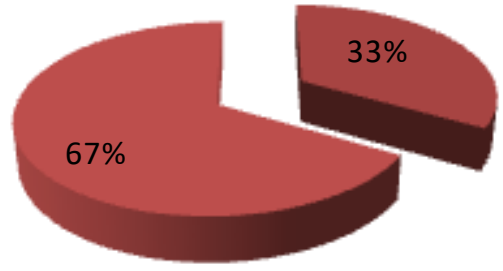

1: Nem discordo e nem concordo

Fonte. Elaborado pelos autores

\section{Considerações Finais}

Este estudo mostrou que a gestão participativa tem a possibilidade de ser implantada na empresa pesquisada, onde o gestor mostrou interesse em adotar o método na sua empresa, pois com relação à comunicação entre gestores e gerentes há um resultado satisfatório onde o gestor da empresa interage bem com os gerentes. As informações fluem parcialmente com naturalidade, sem um impacto negativo.

Dentro do ambiente de trabalho há um grau elevado de confiança entre gestores e gerentes proporcionando assim um ambiente cooperativo, porém as opiniões quanto às tomadas de decisão por meio de grupos que se comunicam estão divididas, no entanto, isso não quer dizer que não haja um ponto positivo para a implantação da gestão participativa, pois novas ideias podem ser discutidas e utilizadas. De acordo com 
Maximiano (1995, p. 88), "Dirigente e pessoas com atitude participativa, empresa participativa".

Durante a análise em relação ás metas e objetivos, por meio de uma maior participação dos funcionários, as mesmas serão alcançadas, pois havendo uma maior coletividade entre gestores e gerentes, o resultado será positivo e eficaz. De acordo com Robbins (2002, p. 188), "a principal característica comum a todos os programas de gestão participativa é a utilização do processo decisório coletivo".

Em relação à valorização das ideias propostas pelos gestores, verificou-se que nem todos os gerentes da empresa fazem uso construtivo delas, mas não podemos generalizar de forma que isto seja um ponto negativo para a implantação da gestão participativa na empresa.

Quando uma organização usa a Gestão Participativa, esta dá oportunidades de um funcionário ser autônomo e mais responsável, proporcionando assim, um bem estar para a empresa e para aqueles que nela trabalham. De acordo com Lerner (1996, p. 33), a participação de cada indivíduo garante uma composição de forças, onde o "todo", trabalhando junto, tenha mais poder do que a soma das partes isoladas.

Todos desejam o sucesso que está efetivamente ao alcance daqueles que o buscarem, preparando-se adequadamente, sempre atentos às ações dos melhores do mercado. Nesse sentido é importante que cada pessoa tenha o seu espaço para desempenhar seu papel com dedicação e responsabilidade.

Conclui-se que para a implantação da gestão participativa requer mudanças de comportamentos não só da chefia, mas também de todos os gerentes vale ressaltar que tomar iniciativa, agir, discutir, questionar e sugerir devem ser ações espontâneas e voluntárias, portanto, sem adequação na empresa não há possibilidade de uma gestão participativa. É importante compreender que a gestão participativa não é uma solução de todos os problemas da empresa e dos colaboradores, não se pode esperar ou estabelecer um padrão de gestão participativa. O sucesso dessa filosofia depende do respeito e no aproveitamento das diferenças entre os indivíduos da organização.

\section{Referências}

BORDENAVE, J. E. D. O que é participação. São Paulo: Brasiliense, 1983.

CERVO, A. L. Metodologia Científica. 6 6 ed. São Paulo: Pearson Prentice Hall, 2007.

CHIAVENATO, I. Gerenciando com as pessoas: Transformando executivo em excelente Gestor de Pessoas. 5ª ed. São Paulo: Manole, 2015.

GIL, A. C. Como Elaborar Projetos de Pesquisa. 4ª ed. São Paulo: Atlas, 2002.

KANAANE, R. Comportamento humano nas organizações: o homem rumo ao século XXI. 2. ed. São Paulo: Atlas, 1999.

LERNER, W. Organização participativa. Mais uma poderosa tecnologia na busca da competitividade. $2^{a}$ ed. São Paulo: Atlas, 1996.

LIMA, J. L. G.; BRYTO, K. K. C. O aumento da produtividade das equipes da Estácio do Pará: as estratégias de liderança, impulsionando o crescimento das equipes. Revista 
de Administração e Contabilidade - RAC, [S.1.], v. 5, n. 10, p. 96-129, dez. 2018. ISSN 2358-1948.

MARANALDO, D. Estratégia para a competitividade. $2^{\circ}$ ed. São Paulo: Produtivismo, 1989.

MAXIMIANO, A. C. A. Além da hierarquia: como implantar estratégias participativas para administrar a empresa enxuta. São Paulo: Atlas, 1995.

MAXIMINIANO, A. C. A. Introdução à administração: $5^{\text {a }}$ ed. São Paulo: Atlas, 2000.

ROBBINS, S. P. Comportamento organizacional. 9. ed. São Paulo: Prentice Hall, 2002.

VÍCTOR, A. do A.; BRYTO, K. K. C. A contribuição da liderança e suas estratégias motivacionais para obtenção de resultado: $O$ caso da Microlins Castanhal-PA. Revista de Administração e Contabilidade - RAC, [S.1.], v. 6, n. 11, p. 1-16, jun. 2019. ISSN 2358-1948. 